\title{
Tuberculoid lymphadenitis due to Mycobacterium chelonei
}

\author{
C. A. MORRIS, G. H. GRANT, P. H. EVERALl, AND A. T. M. MYRES
}

From the Public Health Laboratory, Royal Salop Infirmary Group Laboratory, and Chest Clinic, Shrewsbury

SYNOPSIS An 8-year-old boy developed cervical lymphadenitis four months after an injection of dental anaesthetic. Histology of the lymphatic tissue showed a tuberculoid granulomatous reaction with scanty acid-fast bacilli. Mycobacterium chelonei was isolated in pure culture (NCTC 10882). The patient showed specific skin hypersensitivity to an extract of $M$. chelonei, but not to that of $M$. ranae. This is thought to be the first recorded case of lymphadenitis in man caused by $M$. chelonei; it adds another possibility to be considered in the differential diagnosis of 'a lump in the neck'.

\section{Clinical History}

In February 1972 an 8-year-old schoolboy complained of discomfort in the neck and was found to have a painless soft tissue mass unattached to the skin and deeper tissues below the left angle of the mandible. His temperature was $37 \cdot 4^{\circ} \mathrm{C}$, otherwise he appeared fit. No bony abnormality was found on radiographs of the jaw and a chest radiograph was normal. A course of $125 \mathrm{mg}$ oxytetracycline in syrup four times a day was given for three days, then Co-trimoxazole syrup $(160 \mathrm{mg}$ trimethoprim with $800 \mathrm{mg}$ sulphamethoxazole) twice daily for another three days. As the swelling persisted it was explored surgically and material from it sent to the laboratory. The wound healed uneventfully. Three months later a firm unattached nodule the size of a small pea was palpable beneath the scar; this was still present, but unaltered in size, when the child was seen 10 months after operation.

\section{Investigations}

\section{HAEM A TOLOGY}

No blood was collected preoperatively; a sample collected immediately after the operation showed an erythrocyte sedimentation rate (ESR) of $16 \mathrm{~mm}$ in one hour (Wintrobe); haemoglobin $12.7 \mathrm{~g}$ per $100 \mathrm{ml}$, leucocytes 19000 per $\mathrm{cmm}$, with $89 \%$ neutrophils $7 \%$ lymphocytes, and $4 \%$ monocytes. The serum

Received for publication 19 April 1973. immunoglobulins, $\mathbf{A}, \mathbf{G}$, and $\mathbf{M}$ were normal. The white cell count declined during the following weeks and was 5500 per $\mathrm{cmm}$, with a normal differential four months after operation when the ESR was 11 $\mathrm{mm}$ in one hour.

\section{Histopathology and Microbiology of Biopsied Material}

HiSTOLOGY (FIGURES 1 TO 3 )

Three pieces of lymphatic and fibrous tissue were sent for examination. One was a lymph node with reactive hyperplasia; the other two contained tuberculoid granulomatous areas primarily involving the lymphatic tissue, but sometimes extending into the surrounding connective tissue. The shapes of the granulomata were often sinusoid rather than nodular.

At the centres of the collection of epithelioid cells were small areas of necrosis containing nuclear debris and disintegrating polymorphonuclear leucocytes. No anisotropic material was seen. There were a few giant cells and some very scanty acid-fast bacilli, but no caseation was seen. Atypical tuberculosis was the most likely diagnosis histologically, although, apart from the acid-fast bacilli, the picture resembled more closely a stage in the development of the granulomata of cat scratch fever.

\section{MICROBIOLOGY}

A swab taken at the time of operation was examined. No pus cells or organisms were seen in films stained by the method of Gram and no acid-fast bacilli were 


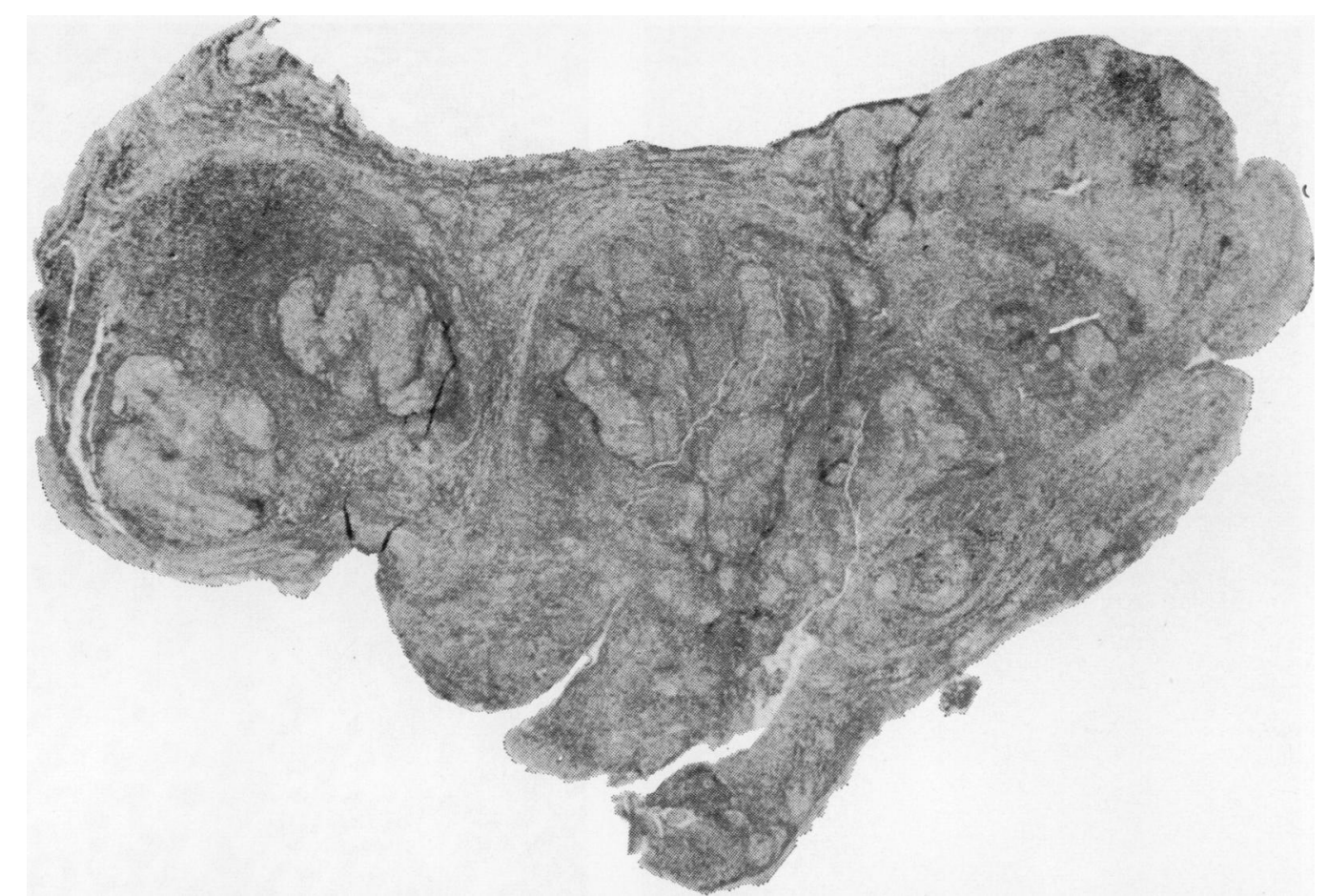

Fig 1 Section of cervical lymph node. Zones of fibrosis separate areas of lymphatic tissue, containing pale granulomata.

found by the Ziehl-Neelsen method. On horse blood agar there was no growth aerobically or anaerobically after 48 hours' incubation at $37^{\circ} \mathrm{C}$. Material, which had been held at $4^{\circ} \mathrm{C}$ for 48 hours until the direct culture results were known, was then inoculated on to two slopes of Lowenstein-Jensen's medium and one of Dorset's egg medium; these were incubated at $37^{\circ} \mathrm{C}$ and examined weekly. There was a growth of 50 colonies or more on all three slopes after four weeks. The culture was pure and the colonies nonpigmented and of butryous consistency. The organisms were bacilli which were strongly acid fast; they were also strongly Gram positive, though some stained irregularly to give a beaded appearance. Subcultures grew rapidly (three to four days) on media containing egg and also on nutrient agar and on MacConkey's lactose bile agar incubated at $37^{\circ} \mathrm{C}$. The isolate was sent to Dr J. Marks of the Tuberculosis Reference Laboratory, Cardiff, who identified it by means of lipid chromatography as Mycobacterium abscessus (synonym $M$. chelonei). The strain has been deposited in the National Collection of Type Cultures where it has been allocated the number 10882. It was highly resistant to streptomycin, isoniazid, PAS, ethionamide, ethambutol, and rifampicin, and also to penicillin, tetracycline, lincomycin, and co-trimoxazole. It was sensitive to erythromycin.

No tubercle bacilli were isolated by culture or by inoculation of material into a guinea pig.

\section{SKIN HYPERSENSITIVITY REACTIONS}

The patient's tuberculin reaction was negative at $1 / 10000$ and weakly positive at $1 / 1000$. He had not been given $\mathrm{BCG}$.

Dr John Stanford of the Department of Bacteriology, Middlesex Hospital Medical School, kindly provided skin test antigens prepared from live sonically disrupted $M$. chelonei and $M$. ranae. The antigens were supplied at a concentration of 1000 units per $\mathrm{ml}$. Just before use the $M$. chelone $i$ antigen was diluted 10 -fold with $0.9 \%$ saline containing Tween $80 \quad 0.0005 \%$ vol $/ \mathrm{vol}$. The $M$. ranae antigen was not diluted. These antigens were inoculated intradermally in $0.1 \mathrm{ml}$ volumes as was also a cat scratch fever antigen and the saline/Tween 80 diluent. There was no response to the $M$. ranae extract, to the cat scratch fever test, or to the saline/Tween 80 diluent. The $M$. chelonei antigen produced a $10 \mathrm{~mm}$ swelling with induration after 72 hours. This had almost disappeared 48 hours later. 


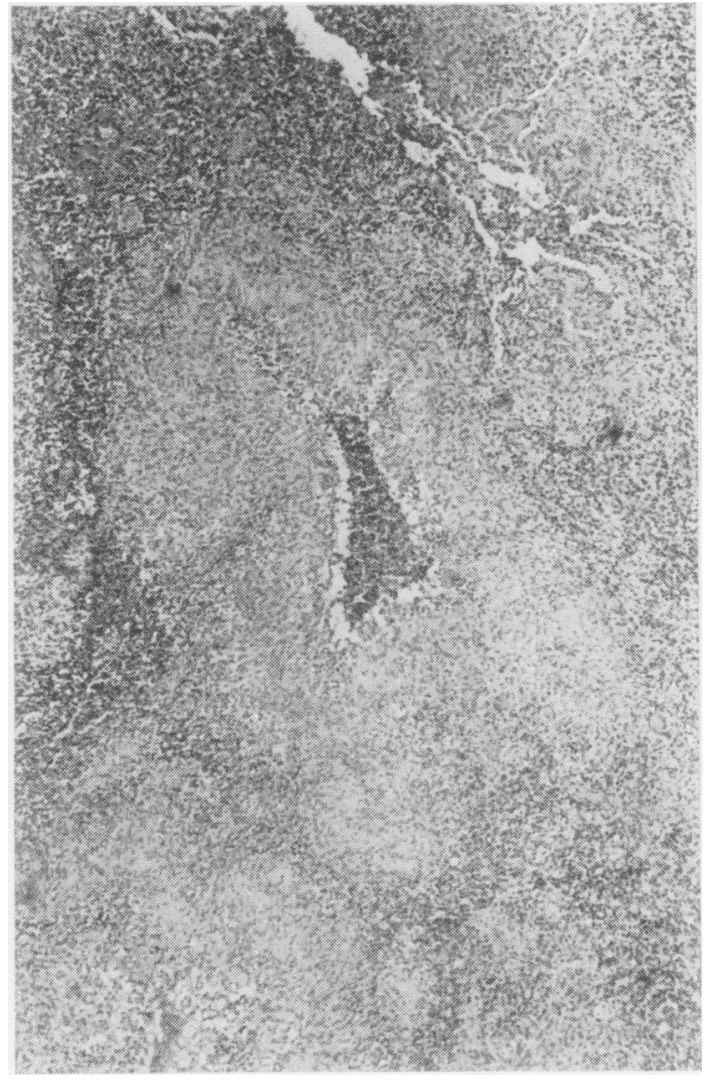

Fig 2

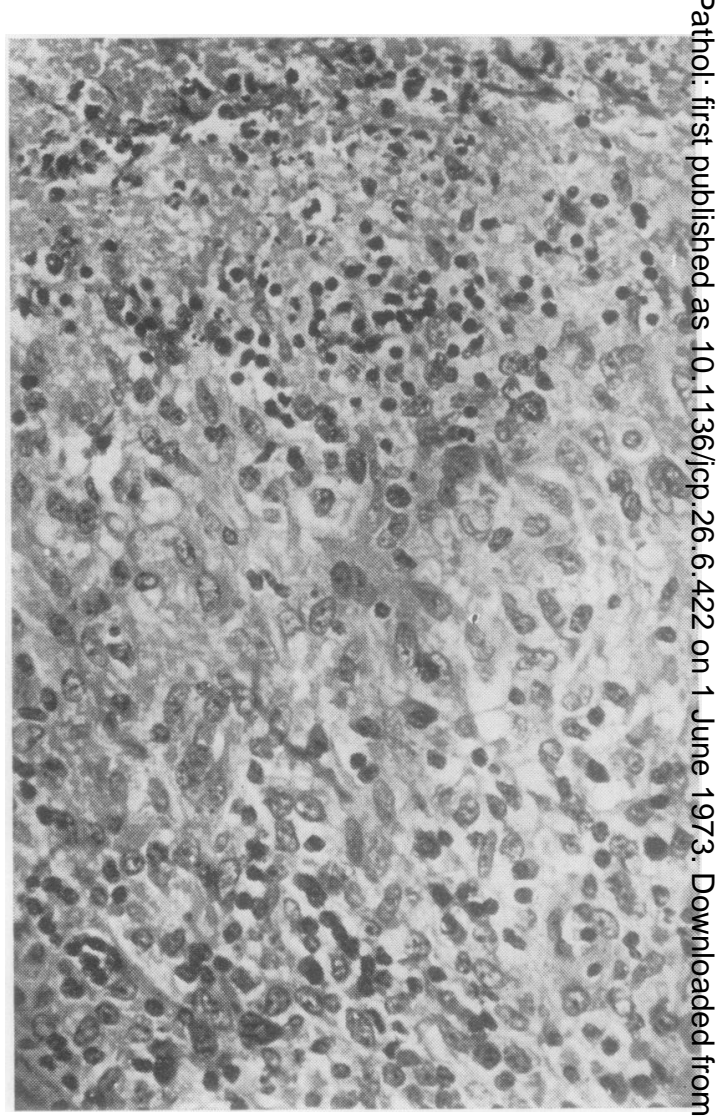

Fig 3

Fig 2 A tuberculoid granuloma in lymphatic tissue. Central necrotic material containing disintegrating polymorphonuclear leucocytes is surrounded by a wider pale zone of epithelioid cells. Haematoxylin and eosin $\times 30$. ?

Fig 3 Cellular structure of a tuberculoid granuloma. Part of a central zone of necrosis containing polymorphonucle $\underline{\underline{\underline{\sigma}}}$. leucocytes is seen at the top right; then a wider pale zone containing many epithelioid cells and occasional giant cells, extending at the bottom into an outer zone which includes plasma cells and merges into normal lymphatic tissue Haematoxylin and eosin $\times 40$.

\section{Likely Source of Infection}

Most human infections with $M$. chelonei have followed the injection of drugs and vaccines. This patient had had a number of injections for immunization against infectious disease, but none during the two years immediately preceding the appearance of the lesion. However, four months before the neck swelling was noted, he had dental treatment for which he was given a local anaesthetic of $2 \%$ lignocaine with $1 / 80000$ adrenaline to produce a left-sided inferior dental nerve block. A single cartridge of anaesthetic was used; no other patients inoculated from the same batch are known to have developed similar lesions and there is no other evidence to suggest that the anaesthetic was cor taminated. It seems likely that the source of ouns patient's $M$. chelonei was his mouth.

\section{Discussion}

Rapidly growing mycobacteria are widely distribut in nature and when isolated from human materif are frequently contaminants of no clinical signif cance. Occasionally they are implicated in superficiad infections and injection abscesses; they can secondary invaders of already diseased lungs (Nicholson and Sevier, 1971; Gruft and Henning, 1972).

Mycobacterium chelonei corresponds to the turt్ţe 
bacillus of Friedmann (1903) and to organisms formerly termed $M$. borstelense, $M$. runyonii and $M$. abscessus (Stanford, Pattyn, Portaels, and Gunthorpe, 1972); it is closely related to another rapidly growing non-pigmented mycobacterium, $M$. fortuitum ( $M$. ranae). These two species have only recently been differentiated satisfactorily by means of immunodiffusion analysis and lipid chromatography (Marks and Szulga, 1965; Stanford and Beck, 1968 and 1969; Jenkins, Marks, and Schaefer, 1971) and their relative importance as pathogens is confused by the earlier accounts of infections in which all isolates are termed $M$. fortuitum. Both species are capable of causing abscesses after the injection of contaminated drugs or vaccines (Cruz, 1938; Limbos, Bretey, Jadin, and Brutsaent, 1961; Vandepitte, Desmyter, Brochier, and Gatti 1962; Owen, Smith, and Coultras, 1963; Beck, 1965; Clapper and Whitcombe, 1967;Canilang and Armstrong, 1968; and Vandepitte, Desmyter, and Gatti, 1969).

Inman, Beck, Brown, and Stanford (1969) described 12 patients in Britain who developed injection abscesses caused by $M$. chelonei after receiving histamine from multidose vials. Typically there was little or no involvement of the axillary lymph nodes, and when these were enlarged they were not painful. The lesions were sometimes multiple and when an abscess discharged there was a tendency for the wound to heal with ugly scarring. In the Netherlands, 50 children developed similar needle track abscesses following injections of quadruple vaccine (Borghans and Stanford, 1973); the abscesses were slow to develop (one to 13 months), were persistent (up to one year), and sometimes required excision. The lesions were painless and the patients had no general symptoms, such as fever or malaise, and no involvement of the regional lymph nodes. In common with these earlier accounts, our patient was quite fit apart from the local lesion, which produced minimal discomfort. The spread of infection to involve regional lymph nodes was unusual and the pathological changes produced in these has not been reported before.

Antibiotics given to our patient produced no measurable improvement. From our experience and reports in the literature it would seem that antibiotics play no part in the treatment of infections by $M$. chelonei. Furthermore, parenteral administration can worsen the situation; Moore and Frerichs (1953) record a knee infection in a patient who on treatment with streptomycin developed multiple gluteal abscesses at the sites of the intramuscular injections. They suggest that these sites provided 'loci minoris resistentiae' which circulating mycobacteria colonized. Accounts in the literature show that spontaneous resolution is usual, though relapse is common and it may be several months before the infection finally resolves. Local excision sometimes speeds recovery.

Histologically in the case of Moore and Frerichs there was a tuberculoid reaction in a gluteal abscess and also, unlike our case, extensive caseation. Our findings more closely resembled those in a woman with cervical lymphadenitis in Malta (Wells, Agius, and Smith, 1955). However, the causative organism in that incident was $M$. fortuitum, which was later more truly identified as $M$. ranae (Stanford and Gunthorpe, 1969). Borghans and Stanford (1973) report on the examination of six human skin abscesses caused by $M$. chelone $i$, which are described as showing 'fistulating, subcutaneous non-specific inflammation with a few small epithelioid cell granulomata, most probably the reaction to necrotic fat tissue'. This differs from the appearances in the present case in which the cervical nodes showed a tuberculoid reaction with sinuous granulomata, reminiscent of cat scratch fever. Our patient, however, disliked and avoided cats. He had no history of being scratched and the cat scratch fever intradermal test was negative.

If the biopsy material from the mass had all been sent in formalin, the tuberculoid appearance and acid-fast bacilli seen in the sections would almost certainly have led to a diagnosis of tuberculosis. Isolation of the organism was essential. Mycobacterium chelonei is unlikely to survive the usual preculture treatment with sodium hydroxide; had this been used the true cause of infection would probably have been missed.

We are grateful to Dr J. Marks for identifying the mycobacterium, Dr J. L. Stanford for providing skin test antigens to $M$. chelonei and $M$. ranae, and Dr C. M. P. Bradstreet for providing antigen for the cat scratch fever intradermal test. Mr. J. D. Hamlet kindly prepared the photographs.

\section{References}

Beck, A. (1965). Mycobacterium fortuitum in abscesses of man. J. clin. Path., 18, 307-313.

Borghans, J. G. A., and Stanford, J. L. (1973). Mycobacterium chelonei in abscesses after injection of diphtheria-pertussis-tetanuspolio vaccine. Amer. Rev. resp. Dis., 107, 1-8.

Canilang, B., and Armstrong, D. (1968). Subcutaneous abscesses due to Mycobacterium fortuitum. Amer. Rev. resp. Dis., 97, 451-454.

Clapper, W. E., and Whitcomb, J. (1967). Mycobacterium fortuitum abscess at injection site. $J$. Amer. med. Ass., 202, 550.

da Costa Cruz J. (1938). Mycobacterium fortuitum. Um novo bacilo acido-resistente patogenico para o homem. Acta med. Rio de J., 1, 297-301.

Friedmann, F. F. (1903). Der Schildkrotentuberkel bacillus, seine Zuchtung, Biologie und Pathogenitat. Zbl. Bakt., I. Abt. Orig, 34, 647-658.

Gruft, H., and Henning, H. G. (1972). Pulmonary mycobacteriosis due 
to rapidly growing acid fast bacillus Mycobacterium chelonei. Amer. Rev. resp. Dis., 105, 618-620.

Inman, P. M., Beck, A., Brown, A. E., and Stanford, J. L. (1969). Outbreak of injection abscesses due to Mycobacterium abscessus. Arch. Derm., 100, 141-147.

Jenkins, P. A., Marks, J., and Schaefer, W. B. (1971). Lipid chromatography and seroagglutination in the classification of rapidly growing mycobacteria. Amer. Rev. resp. Dis., 103, 179-187.

L.imbos, P., Bretey, J., Jadin, J., and Brutsaert, P. (1961). Sur un cas d'abscès à Mycobacterium fortuitum. Ann. Soc. belge Méd. trop., 41, 127-132.

Marks, J., and Szulga, T. (1965). Thin-layer chromatography of mycobacterial lipids as an aid to classification. Tubercle (Lond.), 46, 400-411.

Moore, M., and Frerichs, J. B. (1953). An unusual acid fast infection of the knee with subcutaneous abscess-like lesions of the gluteal region. J. invest. Derm., 20, 133-169.

Nicholson, D. P., and Sevier, W. R. (1971). Mycobacterium fortuitum as a pathogen. Amer. Rev. resp. Dis., 104, 747-750.

Owen, M., Smith, A., and Coultras, J. (1963). Granulomatous lesions occurring at sites of injections of vaccines and antibiotics. Sth. med. J. (Bgham, Ala.), 56, 949-952.
Stanford, J. L., and Beck, A. (1968). An antigenic analysis of the mycobacteria, Mycobacterium fortuitum, Myco. kansasii, Myco. phlei, Myco. smegmatis, and Myco. tuberculosis. J. Path. Bact., 95, 131-139.

Stanford, J. L., and Beck, A. (1969). Bacteriological and serological studies of fast growing mycobacteria identified as Mycobacterium friedmanii. J. gen. Microbiol., 58, 99-106.

Stanford, J. L., and Gunthorpe, W. J. (1969). Serological and bacteriological investigation of Mycobacterium ranae (fortuitum). J. Bact., 98, 375-383.

Stanford, J. L., Pattyn, S. R., Portaels, F., and Gunthorpe, W. J. (1972). Studies on Mycobacterium chelonei. J. med. Micro. biol., 5, 177-182.

Vandepitte, J., Desmyter, J., Brochier, J., and Gatti, F. (1962). Une nouvelle affection à Mycobactèries: l'absces post-injection é M. fortuitum. Ann. Soc. belge méd. trop., 42, 555-560.

Vandepitte, J., Desmyter, J., and Gatti, F. (1969). Mycobacteria, skins and needles. Lancet, 11, 691.

Wells, A. Q., Agius, E., and Smith, N. (1955). Mycobacterium fortuitum. Amer. Rev. Tuberc., 72, 53-63. 